\title{
Brasil y Bolivid por caminos distintos
}

Rodrigo MONTOYA ROJAS

\begin{abstract}
RESUMEN
Una revisión histórico política de dos corrientes distintas dentro del ciclo de gobiernos progresistas en América Latina. Por un lado, el caso de Brasil que atraviesa por una dura crisis política. Por el otro, el caso de Bolivia que sin carecer de coyunturas desfavorables continúa en la brega por mantener y profundizar los cambios con la participación decisiva de las organizaciones populares de El Alto y los pueblos indígenas.
\end{abstract}

Palabras Clave: Brasil, Bolivia, Partido de los Trabajadores, Central Obrera Boliviana, izquierda política, El Alto, Katarismo.

\section{Brazil and Bolivia by different routes}

\begin{abstract}
The essay traces a political and historical review of inner trends in the Latin American welfareoriented government. On the one hand, the case of Brazil, which is undergoing severe political crisis. On the other, the Bolivia case, which faces adverse political issues, nonetheless, keeps going on the struggle to sustain and deepen the Bolivian society shifts with the commitment of social organization from El Alto and the indigenous communities.
\end{abstract}

KEYWORDS: Brasil, Bolivia, Workers Party, Bolivian Workers' Union, left-wing, El Alto, Katarismo.

1 Transcripción de la conferencia "Reflexiones sobre la política en Brasil, Venezuela y Bolivia", presentada en el marco del XXXII Aniversario de la Facultad de Ciencias Sociales de la Universidad Nacional Mayo de San Marcos el miércoles 21 de setiembre de 2016. 


\section{$\mathrm{M}$} i regreso a la facultad para ofrecer una conferencia, después de una larga ausencia, es una oportunidad para agradecer a las nuevas autoridades por su gentil invitación para hablar sobre la política brasileña, boliviana y venezolana. Un tema como este no es frecuente en nuestras aulas. Supongo que una de las razones para esta invitación ha sido mi experiencia de profesor errante, acumulada en los últimos cuarenta años, y mi constante preocupación por el futuro de nuestros pueblos.

Tengo por Brasil un amor muy grande, particularmente una identificación con el Partido de los Trabajadores (PT). He sido profesor visitante en la Universidad de Sao Paulo durante tres años, en momentos distintos. Mi hija Urpi, antropóloga sanmarquina, luego de su doctorado en la Universidad de Sao Paulo, decidió echar raíces en esa tierra vasta y tropical. Tengo dos nietos brasileños que se divierten conmigo diciéndome que algún día jugarán por la selección peruana de fútbol para sacarla del hoyo en el que está. Mi sentimiento de hermandad con Bolivia es muy antiguo. En mis primeros viajes a esa tierra conocida antes como el "Alto Perú", solía decir: soy del Bajo Perú. Decirles soy del Bajo Perú les causaba sorpresa porque era un modo diferente de identificarnos como peruanos, hermanos de los bolivianos. Nosotros tenemos una larga historia común. Es extraordinario ver cómo, en este momento, Brasil pasa por una de las peores crisis de su historia, mientras Bolivia se encuentra muy bien con un gobierno que ha dejado atrás la República de Bolivia para reemplazarla por un Estado Plurinacional. Por su lado, Venezuela va de tumbo en tumbo.

Voy a contarles, brevemente, mi visión sobre estos problemas políticos actuales. Me gustaría partir de dos observaciones previas: la primera es proponerles que cuando examinemos los problemas de los países vecinos y nuestros propios problemas tengamos en cuenta las dos caras de la luna. Quiero decir con esto que no culpemos solamente a la derecha de los problemas de nuestros países, y que volvamos los ojos sobre la responsabilidad de la izquierda. Es más, que comencemos con una visión autocrítica de lo que pasa en la izquierda, porque la derecha hace lo suyo desde que existe y a mí no me corresponde darle consejos sobre lo que debe hacer o lo que no debe hacer. La segunda, es que para examinar los problemas políticos tengamos siempre en cuenta una diferencia profunda entre lo que es la militancia de un partido y el electorado que requiere para ganar una elección y tratar de gobernar un país. Ha sido frecuente oír que hubo en Brasil millones de millones de petistas, confundiendo precisamente militancia y electorado. Con la reciente experiencia peruana, el Frente Amplio logró casi tres millones de votos pero su militancia tal vez sea de apenas diez mil personas. Insisto en observar atentamente esta demografía política para no cometer errores.

\section{8/ REVISTA DESOCIOLOGǴA 26}


La prensa de hoy día trae sobre Brasil una noticia muy grave, una más de las que han venido apareciendo en las últimas semanas. El juez Moro ya aceptó la denuncia que el fiscal hizo contra Lula, hace una semana, acusándolo de ser la "cabeza de una banda para delinquir". La acusación es demasiado grave. Si las cosas marchan como van, tal vez en menos de una semana, el juez aceptará y llamará a juicio a Lula. Luiz Inacio Lula da Silva, o, simplemente, Lula. Fue dos veces presidente de Brasil, habiendo sido un obrero metalúrgico, el migrante pobre que había salido del noreste brasileño a ganarse la vida en Sao Paulo. En 1980, convergieron en la formación del Partido de los Trabajadores, los metalúrgicos y los obreros como un sector clave e importante, intelectuales, grupos de católicos de base, estudiantes, campesinos. Esta confluencia de fuerzas tardó 23 años en llegar al gobierno; perdió tres veces y ganó en la cuarta. Supo prepararse y mantuvo siempre un espíritu unitario. Hubo tendencias marcadas en el partido, pero nunca llevaron a afectar la estructura y la dirección. A diferencia de muchos, Lula hablaba en nombre del proletariado - como suele ocurrir en nuestros países - porque era un obrero de carne y hueso, un metalúrgico, un tornero, que se formó y se cuajó dentro del PT, y llegó a ser un presidente de primera categoría. Cuando terminó su segundo mandato se fue con el $80 \%$ de apoyo. La candidata Dilma Rousseff ganó las elecciones y el PT continuó con un tercer gobierno. Era el éxito de un partido que estaba llevando muy bien sus cosas. Pero al final del último período de Lula aparecieron muy grandes nubarrones en el horizonte, porque el número dos del partido, José Dirceu, el que iba a sustituir a Lula y debió haber sido presidente de Brasil después de Lula, fue llevado a la cárcel por una grave denuncia que probaba la corrupción de un núcleo de gente dentro de la dirección orgánica del PT, que había comprado a un grupo de parlamentarios para que el PT tuviese una mayoría para gobernar con mayor facilidad. El escándalo en brasileño se llamó "o mençalao", que en castellano sería la mensualidadsaza, porque cada uno de los comprados recibía 10 mil dólares mensuales. ¿De dónde salió el dinero para esos pagos? Por canales que no comprometían al todo el PT, pero sí a un núcleo del PT, el dinero salía, seguramente, de las arcas de Petrobras que es la empresa petrolera brasileña, una de las grandes empresas petroleras del mundo.

Les digo desde ahora: estén atentos y atentas a lo que el nuevo gobierno brasileño va hacer con el petróleo brasileño, porque la empresa del petróleo tenía un superávit, era una excelente empresa, iba muy bien y había logrado un hallazgo extraordinario - hace unos años - de un fondo de petróleo bajo el mar brasileño - llamado Presal - con una riqueza extraordinaria de miles de millones de barriles, una extraordinaria fortuna de miles de miles de millones de dólares. Ya 660 mil barriles de petróleo habían salido de este Presal. El PT tuvo la extraordinaria sabiduría 
de tomar tres decisiones sobre el petróleo brasileño, en particular, sobre esta gran nueva fuente de petróleo. Una, ese petróleo será explotado única y exclusivamente por Petrobras. Dos, la tecnología que se use será brasileña con el apoyo de otras empresas y técnicos que vengan a ayudar y trabajar con Petrobras. Tres, que al explotar su petróleo, Petrobras no permitirá que ninguna empresa extranjera de petróleo se asocie o busque asociarse con Petrobras. Las grandes empresas petroleras del mundo querían asociarse ya con Petrobras, porque sabían que en Presal hay una mina extraordinaria de petróleo que ellos no querían dejar pasar.

En medio de este panorama extraordinario para Brasil apareció un fenómeno trágico: la corrupción, que no reconoce fronteras, ni colores. Este flagelo que corroe el mundo entero está en todas partes. La cárcel de José Dirceu estaba revelando algo importantísimo, un poder judicial brasileño suficientemente fuerte y autónomo como para encarcelar al líder número 2 del PT y futuro presidente del país. A pesar de este duro golpe, el PT volvió a ganar el segundo gobierno con Dilma Rousseff. Lula no había terminado aún su segundo gobierno cuando estalló el gran escándalo: el caso de "Lava Jato", que quiere decir, lavado de automóviles. Este Lava Jato es un gigantesco acto de corrupción. Se descubrió que al interior de las grandes empresas constructoras brasileñas como Odebrecht, hubo divisiones internas con la exclusiva finalidad de financiar la corrupción de altos jefes, de altos dirigentes brasileños que fueron cayendo uno a uno por haber recibido coimas con dinero proveniente de Petrobras. Caerán también varios ejecutivos peruanos y otros latinoamericanos, un par de presidentes o por lo menos uno. Todo parece haber comenzado con los grandes proyectos de infraestructura y energía, propuestos por la iniciativa para la Infraestructura Regional Suramericana (IIRSA) imaginado en el año 2000 por el famoso sociólogo de la teoría de la dependencia Fernando Henrique Cardoso, en su segundo mandato como presidente del Brasil. Él comprometió a todos los presidentes de los países vecinos de América del Sur, entre ellos a Alejandro Toledo, a realizar diez grandes proyectos de infraestructura (carreteras, entre ellas las llamadas interoceánicas, y grandes hidroeléctricas) que el Brasil necesita para llevar la soya, su producto estrella, a los mercados de China e India y para cubrir sus necesidades futuras de electricidad. La propuesta de Fernando Henrique Cardoso sobre la necesidad de contar con grandes proyectos de desarrollo, fue rápidamente oída y aceptada para ofrecer recursos y contar con la inversión brasileña a través del Banco Nacional de Desarrollo del Brasil que tiene más dinero que todo el Banco Mundial. Para hacer las carreteras e hidroeléctricas, las grandes empresas brasileñas de construcción aparecieron por todas partes y con ellas los conflictos. Por ejemplo: Bolivia rechazó la construcción de una hidroeléctrica en su territorio con una lógica inaceptable: daño físico y ambiental para Bolivia y beneficio de luz para Brasil.

\section{0/ REVISTA DE SOCIOLOGíA 26}


Brasil es un país diverso y muy rico, con una tasa de desigualdad muy alta, tiene una población de 220 millones de personas, es un país inmenso, con un desarrollo capitalista fuerte, con una industria sólida, fabrica aviones y barcos, exporta carne, soya y otros productos como naranjas. Puedo ofrecerles un breve ejemplo de su riqueza, pertinente porque estamos en San Marcos. En 1992 el Estado de Sao Paulo —el más rico del país - becaba a 4 mil estudiantes de doctorado por año con becas de 4 años para estudiar los doctorados que quisieran y ofrecía después una beca de postdoctorado para que los flamantes doctores vayan a buscar el trabajo que quieran en las instituciones que quieran, pagando el Estado de Sao Paulo el sueldo de un año, con el compromiso asumido por las instituciones o las empresas de contratarlos después si estaban interesadas en sus servicios. ¿Parece una especie de sueño, verdad? ¡Qué maravilloso sería si algo parecido ocurriese aquí en Perú y en San Marcos!

El segundo gran golpe para el PT ocurrió cuando la prensa adversaria explotó a comienzos de este año otro gran escándalo al dar los nombres de personas ligadas al PT y a Petrobras, nuevos dirigentes, nuevas personas directamente ligadas al PT comprometidas con las coimas de algo así como seis mil millones de reales salidos de las arcas de Petrobras y enviadas a través de los paraísos fiscales como Panamá a empresas especialmente creadas para recibir el dinero y, luego, transferirlos a otras cuentas, en un carrusel muy rápido que en la mayoría de casos logra desaparecer las pistas de los beneficiarios.

La fiscalía y los jueces brasileños lograron identificar plenamente el caso de la empresa Odebrecht, cuyo gerente central está condenado a algo más de veinte años de cárcel, prometiendo rebajar las penas a los cómplices que cuenten lo que efectivamente ocurrió. El caso de ECOTEVA en Perú (directamente vinculado con el expresidente Toledo) permite entender lo que pasó en Brasil con la enorme diferencia de que en Perú los responsables parecen fantasmas.

El expresidente Lula ha sido acusado de haber sido beneficiario también de esta corrupción con los fondos de Petrobras; se defiende argumentando: "yo no recibí un solo real, nadie me puede probar que he recibido un solo real y si un día me lo prueban yo mismo me iré caminando a la comisaría". Aquí se abre un capítulo interesante para que los estudiantes puedan ver de cerca la lógica del poder. Dentro de la gran complejidad del concepto poder se encuentra una sección o capítulo que se denomina la "tentación del poder". Desde el poder se maneja mucho dinero. A Lula se le acusó de haber recibido una casa de campo enorme a dos horas de Sao Paulo y un departamento de lujo en una playa entre Sao Paulo y Río de Janeiro, que las empresas le habrían construido para él. Como buen brasileño, a Lula le encanta hacer los domingos sus churrascos (asados o parrillas). Al codearse con los empresarios es posible que a Lula le haya gustado el wisky. Parece cierto que la familia de Lula, 
y él mismo, disfrutaron de esa casa de campo y de ese departamento en la playa, cuya propiedad no es de Lula ni de su esposa, hijos o familiares. Los sabuesos de la prensa han seguido y perseguido día a día quienes llegan allí y quienes se divierten, quienes comen, qué comen, qué beben y qué bailan. La conclusión simple fue: "son propiedades de Lula".

El PT cometió un grave error: desde el principio, con la fuerza que tenían, con los recursos de sus militantes el PT pudo haber creado un periódico de izquierda, un canal de televisión, una radio. Prácticamente todos los medios de comunicación están contra Lula y el PT y buscan por todos los medios impedir que Lula vuelva a ser candidato a la presidencia. Mis amigos del PT en Sao Paulo lamentan que el partido no tuviese sus propios medios de comunicación, que en un momento como éste habrían servido para contrarrestar la enorme influencia de los medios de la derecha.

¿Cuál ha sido el efecto de estos dos grandes escándalos de corrupción en los militantes del PT y en los votantes del PT? Al interior del PT ha causado un inmenso dolor y una sensación de haber perdido, de no tener horizonte, de no saber qué hacer. Entre los electores y votantes del PT, menos comprometidos con el PT, la desesperanza es muy grande, muy dura. Nada de esto significa que el PT no esté en condiciones de responder con sus marchas en las calles, pero los golpes recibidos han sido demasiado fuertes. Como sabemos, en política los errores se pagan.

La derecha está siempre dispuesta a tentar a los cuadros débiles de los partidos de izquierda, para atraparlos por donde son más frágiles y por donde pueden caer con más facilidad. La izquierda debiera, obviamente, cuidarse y estar muy atenta para que eso no ocurra, pero es suficiente que alguien pique el anzuelo para que la derecha desarrolle una campaña de desprestigio que llega a la gente, a los electores y que debilita a los militantes, hasta el extremo de que muchos de estos deciden apartarse de la militancia y de la política.

Para cerrar la sección sobre Brasil, quisiera decirles que estemos todos atentos a lo que el nuevo gobierno de la vieja derecha brasileña (Temer) haga con el petróleo brasileño. La privatización de Petrobras y la entrega de la gran reserva de petróleo en El Presal a las empresas multinacionales del capitalismo es inminente, es casi inevitable, porque Petrobras no está en buena situación por todo lo que ha pasado. Me parece lamentable que el gran sueño del pueblo brasileño de reservar el petróleo para Brasil y no para las grandes empresas extranjeras sea reemplazado por la misma fórmula de siempre: las grandes empresas petroleras llevándose el $80 \%$ de la producción dejando solo un $20 \%$ para el país. Recuerdo el entusiasmo de mis amigos del PT cuando creían que muy pronto podría cumplirse la promesa de Lula de consagrar el $30 \%$ de los ingresos del petróleo a la educación y la salud públicas.

\section{2/ REVISTA DESSOCOLOGGíA 26}




\section{El caso de Bolivia}

Bolivia es un país como si fuera el mío. He jaraneado con los amigos y amigas bolivianas, he estado, muchas veces allí. Tengo una atención permanente por lo que pasa en Bolivia. Recomiendo a los jóvenes que escuchan esta conferencia que Bolivia debiera ser vista con mayor atención. Los bolivianos fueron los primeros que hicieron una revolución en 1952, y que arreglaron cuentas con los terratenientes. Antes de abordar el tema sugiero algunas observaciones previas para entender el caso boliviano. Una, todo el país sufre por haber perdido su mar arrebatado por Chile. El 23 de marzo de cada año todos los bolivianos y bolivianas marchan pidiendo el regreso de su litoral, la recuperación de por lo menos una parte de los 600 kilómetros de Costa que perdieron. Hay, por eso, una herida abierta, la Corte Internacional de La Haya ha aceptado la solicitud para volver a mirar el tema de la frontera de Chile.

El segundo elemento histórico para entender Bolivia es la Central Obrera Boliviana (COB). El único sindicato de América Latina que nunca se partió es la Central Obrera Boliviana, toda una institución. La COB era la central de los sindicatos mineros cuando la minería era la gran fuente de la economía del país. La COB era una especie de gran institución, una especie de gobierno paralelo a los gobiernos existentes, su opinión era clave para todo. Desde su fundación fue manejada con un principio fundamental: "La COB no se divide, fuera de la COB divídanse como quieran". Hay dentro de la COB corrientes políticas de todos los colores de la izquierda: desde el antiguo PC hasta los trotskistas. Esa unidad sindical se ha mantenido desde 1946 hasta ahora. Ya no tiene el mismo peso de antes pero sigue siendo la COB. Por su origen de central sindical minera, la COB miró de lejos y con desdén a los campesinos e indígenas, a pesar que los obreros mineros tenían también un predominante origen campesino e indígena. Lo mismo ocurrió en Perú en tiempos del Partido Comunista y su presencia hegemónica en la Central General de Trabajadores del Perú (CGTP).

El tercer factor clave para entender Bolivia es el fenómeno del katarismo. En 1990 la mayor parte de bolivianos eran kataristas, menos la derecha, la misma que en determinadas circunstancias tuvo que reconocer su importancia. ¿Qué era el katarismo? Tomás Katari y Túpac Katari fueron los dos grandes dirigentes aimaras de la revolución anticolonial más importante de América, esa que Túpac Amaru condujo desde el Cusco. Después de la muerte de Túpac Amaru, el 18 de mayo de 1782, la gran rebelión marchó hacia el sur, primero en Azángaro, luego en Oruro, Chayanta y en La Paz. Tomás Katari se sintió identificado con la revolución anticolonial dirigida por Túpac Amaru reconocido como Inca y Rey. Con la utopía andina en su expresión más cabal, Túpac Amaru se declaró "Inca Rey", heredero de los incas y con derecho al incario porque él tenía el mismo apellido y con la línea genealógica de Túpac Ama- 
ru I, asesinado en la Plaza del Cusco en 1572. Túpac Katari tenía otro nombre, y lo abandonó para llamarse Túpac, como Túpac Amaru, y Katari como Tomás Katari. Los dirigentes indígenas y campesinos, así como los intelectuales reivindicaron el papel de Tomás y de Túpac Katari en Bolivia para señalar sin ambigüedad alguna que entre la Bolivia blanca, europea o qara (desnuda en quechua y en aimara) los bolivianos debían escoger el lado indio de su historia.

Mientras que en el lado peruano Túpac Amaru era un cacique que pertenecía a la aristocracia indígena, y gozaba de grandes privilegios concedidos por la corona, Tomás y Túpac Katari eran indios de abajo, eran simplemente "indios del común", comunarios opuestos a los españoles, a los criollos, a los curas y también a los caciques indios abusivos y a los mestizos impuestos como caciques. Túpac Amaru tuvo la finura de no romper plena y totalmente con el rey de España, dijo que no enfrentaría al Rey de España, que el Rey de España le había dado directivas para que él las cumpla. Sin embargo, en Cusco y las provincias peruanas de la rebelión, los indígenas tenían una posición radical, muy parecida a los aimaras de Bolivia. Mientras Túpac Amaru trataba bien a la iglesia, los aimaras de Bolivia enfrentaron a los criollos, a los españoles, a los curas, y llegaron a la conclusión de que los indios y las comunas o comunidades serían el nuevo rey. Sinclair Thomson, un historiador de Nueva York, ha publicado un libro bellísimo sobre la revolución anticolonial de los aimaras en Bolivia². Si solo reinasen los indios habría justicia, habría libertad, no habría explotación, no habría iglesia católica, no habría curas, no habría encomenderos, etc. Este movimiento indígena boliviano fue muy fuerte y radical, comprometió y sacudió todo el país.

La historia de esa gran rebelión anticolonial habría quedado en el olvido si el katarismo no lo hubiese reconocido como suyo. El katarismo fue entre los años $1960 \mathrm{y}$ 2000 un estado de ánimo, una convicción profunda de la mayoría del pueblo boliviano para mirarse las caras en un espejo y reconocerse como indios o descendientes de indios, como los Katari, dejando atrás la vergüenza, asumiendo que el componente indio de Bolivia debe ser el punto de partida para resolver sus problemas.

Con ese espíritu rebelde, surgió en la última década del siglo XX, un joven cocalero aimara llamado Evo Morales, nacido en una comunidad muy cercana al lago Titicaca. Sin horizonte alguno para encontrar un empleo se fue a trabajar en la producción de la coca. Era un joven fuerte, según las bolivianas aimaras era uno de los hombres más guapos de Bolivia, y tenía una gran afición por el fútbol. No sé si lo recuerdan, cuando Evo Morales viene de visita al Perú, asiste a todas las citas pero separa una tarde para jugar fútbol. Juegan los bolivianos de un lado y los peruanos del otro. Este

Thomson, Sinclair. Cuando solo reinasen los indios. La Paz: Muela del diablo. 2006.

\section{4/ REVISTA DESSOCOLOGGíA 26}


hombre, con una gran juventud, con una gran fuerza física, sin ninguna formación escolar ni universitaria ni nada, se convirtió en un líder cocalero. Los líderes de los cocaleros lo nombraron candidato para que en Bolivia fuese diputado y Evo Morales salió elegido. La derecha tonta cometió el error de atacar a Evo Morales, acusándolo de narcotraficante. Él solo era un productor de coca, nada más. No era productor ni comerciante de cocaína. Tampoco la consumía, salvo las hojas de coca en los grandes ritos y ceremonias. Esta acusación produjo una indignación muy grande en el sindicato de cocaleros. Su protesta colocó a Evo Morales en el escenario político del país, porque siendo un diputado y acusado de narcotráfico, lo metieron a la cárcel y le quitaron la condición de diputado. Estando preso Evo Morales fue elegido como candidato al senado, ganó la senaduría y salió de la cárcel para ocupar su silla de senador.

Permítanme que les cuente una anécdota. En una entrevista con periodistas bolivianos me preguntaron: ¿qué piensa usted de la inminente llegada de Evo Morales a la presidencia de Bolivia después de ser elegido senador? De acuerdo con las reglas constitucionales de la época en Bolivia, el presidente era escogido por el Congreso $y$, alguien que fue tercero en las elecciones puede ser elegido presidente, si hay un acuerdo de las fuerzas dentro del Congreso. Por ese camino, Evo Morales podía ser elegido presidente de Bolivia. Contesté diciéndole: recen un padre nuestro para que Evo Morales no salga presidente, porque no tiene un partido sólido ni un equipo de gente. Para gobernar un país como Bolivia habría que contar con un mínimo de 3 mil personas para ocupar los puestos de dirección en todos los niveles del país. Sin eso no se puede gobernar. Felizmente, no fue escogido como presidente y el Movimiento al Socialismo (MAS), fundado por Evo, supo esperar y prepararse durante cuatro años para luego ganar la presidencia con dos tercios de los votos, algo que no se ve en la mayoría de países de América Latina. Una de sus primeras decisiones fue convocar a la Asamblea Constituyente.

Llegados a ese punto, es pertinente referirnos a otro elemento clave para tratar de entender Bolivia, El Alto es la zona que está encima de La Paz, es el nombre del aeropuerto de La Paz. Hace cuarenta años allí solo había una puna fría y un aeropuerto, nada más. La ciudad de La Paz está, entre 3000 y 3600 debajo de El Alto. Con el crecimiento urbano de la ciudad la gente no tenía a dónde ir y comenzó a poblar los alrededores del aeropuerto. Hoy es la ciudad El Alto, que ya tiene más habitantes que La Paz. Evo Morales ha creado un nuevo medio de transporte para atravesar la ciudad de La Paz por el aire y llegar en quince minutos a El Alto, como si se subiese a un campo europeo de sky. En lo que parecen canastas aéreas con ocho personas por viaje (como en las antiguas y actuales oroyas peruanas para atravesar los ríos), subiendo o bajando, gracias a un juego de cables, de vuelo libre, sin semáforos, sin molestar a nadie. 
La ciudad El Alto surgió por obra de los pobres echados de la propia ciudad de La Paz y echados del campo; migrantes todos. Tuvieron una fuerza política para fundar un pueblo, una ciudad. Lo más cercano a eso en el Perú es Villa El Salvador. En El Alto vivían los que trabajaban en La Paz: obreros, comerciantes, estudiantes, profesores, electricistas $y$ todos los oficios que podemos imaginar. Estos oficios supieron organizarse muy bien. Dieron una gran batalla contra una empresa francesa, que descubrió que el agua de los nevados - tan pura y tan limpia - podía llevarse a Francia con una marca original llamada Inti Illimani: que es el nombre del nevado precioso, el Apu, padre protector de los habitantes de La Paz y de El Alto. Pero un gran cabildo de vecinos de El Alto organizó un movimiento para que la empresa se vaya de Bolivia. La empresa tuvo que irse y el agua queda en su sitio, así como el nombre del Apu no será más una marca comercial. El Alto tenía una fuerza política muy grande. Cuando los bolivianos tomaron la decisión de echar a Sánchez de Lozada, el minero millonario y presidente boliviano, hubo una batalla suficientemente decisiva para que Sánchez de Lozada tome un avión y regrese a Estados Unidos.

En su campaña electoral Evo Morales logró el apoyo de los obreros, de los campesinos, de gran parte de los intelectuales, de mucha gente de La Paz, pero no tenía el apoyo de El Alto. En un cabildo o asamblea política la gente de El Alto le dijo: Evo, vamos a votar por ti con dos condiciones: lo primero que vas a hacer es llamar a una asamblea constituyente para cambiar la constitución y convertir a Bolivia en un Estado Plurinacional. Evo bajó la cabeza y dijo: me comprometo. La segunda condición fue igual de importante: tienes que nacionalizar los hidrocarburos, porque los gringos se llevan desde hace muchísimo tiempo lo principal de la riqueza boliviana, y tú tienes que encargarte de esa nacionalización. Evo Morales respondió: sí, lo voy a hacer. Evo ganó la presidencia con el $66 \%$ de los votos, Convocó a una asamblea constituyente, formada con representantes de indígenas, de los Andes y de la Amazonía, se llenó de indios, y de cada una de las capas sociales de Bolivia. El resultado fue una constitución que cambió el nombre de Bolivia y todas sus reglas políticas de juego. Si se me permite voy a citar de la nueva Constitución, el preámbulo:

En tiempos inmemoriales se erigieron montañas, se desplazaron ríos, se formaron lagos. Nuestra Amazonía, nuestro chaco, nuestro altiplano, nuestros llanos y valles se cubrieron de verdores y flores. Poblamos esta sagrada madre tierra con rostros diferentes y comprendimos desde entonces la pluralidad vigente de todas las cosas y nuestra diversidad como seres culturales, así conformamos nuestros pueblos y jamás comprendimos el racismo hasta que lo sufrimos desde los funestos tiempos de la colonia.

El pueblo boliviano de composición plural, desde la profundidad de la historia, inspirado en las luchas del pasado, en la sublevación indígena anticolonial, en

\section{6/ REVISTA DESSOCOLOGGíA 26}


la independencia, en las luchas populares de liberación, en las marchas indígenas, sociales y sindicales, en las guerras del agua y de octubre, en las luchas por la tierra y el territorio, y con la memoria de nuestros mártires construimos un nuevo Estado.

Un Estado basado en el respeto e igualdad ante todos, con principios de soberanía, dignidad, complementariedad, solidaridad, armonía y equidad, en la distribución y redistribución del producto social, donde predomine la búsqueda del vivir bien, con respeto a la pluralidad económica, social, jurídica, política y cultural de los habitantes de esta tierra, en convivencia colectiva con acceso al agua, trabajo, educación, salud y vivienda para todos.

Dejamos en el estado colonial, republicano, neoliberal, asumimos el reto histórico de construir colectivamente el Estado unitario social de derecho plurinacional comunitario, que integra y articula los propósitos de avanzada hacia una Bolivia democrática, productiva, portadora e inspiradora de la paz, comprometida con el desarrollo integral y con la libre determinación de los pueblos.

Nosotros, mujeres y hombres, a través de la Asamblea Constituyente y con el poder originario del pueblo manifestamos nuestro compromiso por la unidad e integridad del país.

Cumpliendo el mandato de nuestros pueblos, con la fortaleza de nuestra Pachamama y gracias a Dios fundamos Bolivia.

Honor y gloria a los mártires de la gesta constituyente y liberadora que han hecho posible esta nueva estructura ${ }^{3}$.

Asimismo, el capítulo primero de la Constitución dice:

Artículo 1. Bolivia se constituye en un Estado Unitario Social de Derecho Plurinacional Comunitario, libre, independiente, soberano, democrático, intercultural, descentralizado y con autonomías. Bolivia se funda en la pluralidad y el pluralismo político, económico, jurídico, cultural y lingüístico, dentro del proceso integrador del país ${ }^{4}$.

Se trata de una constitución nueva, que deja la República de Bolivia en el pasado y crea un Estado Plurinacional de Bolivia en el presente. Me parece útil citar aquí al padre Xavier Albo, catalán, amigo mío a quien le tengo mucho cariño, antropólogo, que llegó a Bolivia hace cincuenta años. Se nacionalizó boliviano, aprendió el aimara y el quechua, y es el cura que ha acompañado muchas de las luchas de su tiempo. Estuvo en parte de la Marcha por el territorio y la dignidad, en 1990, que los indíge-

3 Constitución política del Estado plurinacional de Bolivia. La Paz: Asamblea Constituyente de Bolivia, 2008, 2. Recuperado de: http://www.comunicacion.gob.bo/sites/default/files/docs/Nueva_Constitucion_Politica_del_Estado_Boliviano_0.pdf

4 Constitución política del Estado plurinacional de Bolivia. La Paz: Asamblea Constituyente de Bolivia, 2008, 3. Recuperado de: http://www.comunicacion.gob.bo/sites/default/files/docs/Nueva_Constitucion_Politica_del_Estado_Boliviano_0.pdf 
nas del oriente (Beni, parte de la Amazonía) hicieron para que en La Paz los vean y escuchen por primera vez. Participó también en el debate de la constituyente. Al conversar sobre la nueva Constitución Xavier Albó, me dijo: "Bolivia se encuentra en una situación de cambio muy grande, porque aquí se respeta a todas las naciones, y la derecha dice: nos han quitado nuestra nación. Todos han recuperado sus naciones y nosotros hemos perdido nuestra nación, porque la nación boliviana era de ellos, y no lo de los de abajo. Los indígenas dicen "nuestras naciones", porque son naciones distintas, ahora somos nosotros los que mandamos y ya no hay más la República de Bolivia".

La Asamblea Constituyente busca un Estado diferente. En materia económica, Evo nacionalizó los hidrocarburos, una decisión indispensable para el éxito económico de Bolivia en los últimos años. Hasta el 2003, en Bolivia las empresas se llevaban el $82 \%$ de la ganancia producida por los hidrocarburos, y el Estado Boliviano recibía el 18\%. En la negociación para lograr el apoyo de El Alto, El Alto le recomendó a Evo que invierta los términos: que los gringos se lleven el $18 \%$ y que el $82 \%$ se quede con el Estado Plurinacional de Bolivia. Evo pensaba en ese momento que la proporción adecuada sería 50\%-50\%. Pero los de El Alto le dijeron: no. Finalmente, por lealtad con sus electores Evo invirtió los términos: El Estado pasó de 18 a 82\% y las empresas de 82 a 18\%. La derecha boliviana y también la peruana pegaron un grito al cielo. Dijeron que no llegarían nuevas inversiones, que las empresas abandonarían el país y que la economía boliviana marcharía al desastre. Las empresas no se fueron, aceptaron quedarse con el $18 \%$, aceptaron renegociar otras cosas, porque la relación entre Estado y empresa es más que eso. Así, el Estado se quedó con el $82 \%$. Con ese dinero el gobierno empezó a hacer obras para responder las expectativas del pueblo boliviano. Junto con Panamá, y Perú, Bolivia es uno de los tres países que en mejor estado están en medio de la crisis en el mundo y en el continente. Ha sido posible cambiar de política, cambiar de Constitución, convertir a todos los indios en ciudadanos bolivianos de un Estado propio nuevo, y tener las empresas, tener el dinero suficiente para que el Estado pueda ir adelante.

Como muchos de ustedes pensarán con razón "no todo es color de rosa". El gobierno de Evo también tiene sus contradicciones. Me parece que Evo cometió el error de competir por cuarta vez en las elecciones; me parece también que Evo cometió el error junto con su partido de no crear las condiciones para un liderazgo que tome la posta luego de él, más aún, si sabemos que el vicepresidente Alvaro García Linera ha acompañado a Evo Morales desde el comienzo. Hablando de quién podría sucederlo, Evo respondió"ya veremos", como si no tuviera a nadie. Grave error. Perdió la consulta para un cuarto gobierno, por no tener la sabiduría de dar la posta dentro del mismo partido a otra persona con suficiente capacidad para gobernar.

\section{8/ REVISTA DE SOCIOLOGǴA 26}


Hay en Bolivia una gran reserva dentro de la Amazonía boliviana que se llama el Tipnis, y se había llegado a un acuerdo para que una empresa construyese una gran carretera que divida el gran Parque Nacional en dos. Supongo que ustedes ya saben, 0 debieran saber, que cuando se construye un kilómetro de carretera en la Amazonía, se destruye cuarenta kilómetros de bosque a la derecha y cuarenta kilómetros de bosque a la izquierda, porque ahí aparecen los colonos como hongos, que traen ganado y forman empresas y comienza la siembra de productos comerciales. La Amazonía deja de ser la Amazonía, el bosque deja de ser bosque. El cambio climático tiene también que ver con la ininterrumpida destrucción de los bosques en todo el continente. El movimiento indígena amazónico, que tiene la misma edad de AIDESEP, movimiento amazónico nuestro, y la Confederación de Pueblos Indígenas del Oriente Boliviano (CIDOB) le dijo a Evo: "No queremos esa carretera, esa carretera nos va hacer daño, va hacer desaparecer pueblos indígenas que todavía están lejos, que no quieren juntarse con nosotros, porque nosotros representamos las pestes, las enfermedades y la muerte". Evo Morales dio marcha atrás, prometió no construirla pero, luego, volvió a autorizar su construcción por una empresa brasileña. Es posible que haya un acuerdo del gobierno boliviano con la empresa brasileña, un contrato que no se puede romper en términos sencillos. El pueblo amazónico insiste: no queremos la carretera en la Reserva del TIpnis. No sabemos cómo se resolverá el problema.

Lamento que no haya tiempo para decir nada sobre Venezuela, ustedes han pasado toda la mañana y tarde trabajando. Mi tiempo ha terminado. Muchas gracias por su paciencia. 